\title{
MATERNAL NEAR MISS- AN INDICATOR OF MATERNAL HEALTH IN A TERTIARY CARE HOSPITAL OF ODISHA
}

\author{
Bharati Panda1, Smita Kumari Panda², Durga Madhab Satapathy³, Rudra Prasanna Mishra ${ }^{4}$
}

${ }_{1}^{1}$ Assistant Professor, Department of Community Medicine, VIMSAR, Burla, Odisha.

${ }^{2}$ Associate Professor, Department of Community Medicine, VIMSAR, Burla, Odisha.

${ }^{3}$ Professor and HOD, Department of Community Medicine, VIMSAR, Burla, Odisha.

${ }_{4}^{4}$ Postgraduate Resident, Department of Community Medicine, VIMSAR, Burla, Odisha.

\section{ABSTRACT}

\section{BACKGROUND}

Maternal near miss is higher in developing countries and causes are similar to those of maternal mortality namely haemorrhage, hypertensive disorders and sepsis.

Objectives-

1. To estimate the burden of maternal near miss in 0 and G Dept. of VIMSAR, Burla in terms of proportion and near miss indicators.

2. To assess the foetal outcome of patients with maternal near miss.

\section{MATERIALS AND METHODS}

It was a record-based cross-sectional study conducted in the Department of O and G, VIMSAR, Burla from July 2017 - Dec 2017. Cases were defined based on WHO criteria. Relevant data was collected from case records of maternal near miss patients.

\section{RESULTS}

Out of 1406 deliveries, near miss cases were 89. Total live births during the study period were 1349 and there were 8 maternal deaths. Maternal mortality ratio was 593/ 100,000 live births. Maternal near miss incidence ratio was 65.95 and Mortality index was 8.2. Preeclampsia was the leading cause (40.4\%) of morbidity of near miss cases followed by severe anaemia (29.2\%) and eclampsia (19.1\%).

\section{CONCLUSION}

Near miss approach helps to evaluate and improve the quality of care provided by health system by identifying the pattern of severe maternal morbidity and mortality, strengths and weaknesses in the referral system and the way in which improvement can be made.

\section{KEYWORDS}

Maternal Mortality, Near Miss, World Health Organisation, Near-Miss Approach.

HOW TO CITE THIS ARTICLE: Panda B, Panda SK, Satapathy DM, et al. Maternal near miss- an indicator of maternal health in a tertiary care hospital of Odisha. J. Evolution Med. Dent. Sci. 2018;7(12):1443-1446, DOI: 10.14260/jemds/2018/328

\section{BACKGROUND}

According to Millennium Development Goal (MDG) in 2015 the goal number five was to improve the maternal health which was falling way below our target. Our aim in reducing maternal mortality by $75 \%$ has not been met with MDG. ${ }^{1}$ Maternal and child health care is one of the eight basic components of primary health care in declaration of AlmaAta. 2,3 Maternal mortality (MM) is frequently described as "Just the Tip of the Iceberg" alluding that there is a vast base to the iceberg in the form of maternal near miss (MNM), i.e. maternal morbidity which has remained largely undescribed. 4

A maternal near miss (MNM) is an event in which a pregnant woman comes close to maternal death, but does not die - a "near-miss." Traditionally, the analysis of maternal deaths has been the criteria of choice for evaluating women's health and the quality of obstetric care.

'Financial or Other Competing Interest': None.

Submission 06-02-2018, Peer Review 03-03-2018,

Acceptance 09-03-2018, Published 19-03-2018.

Corresponding Author:

Dr. Rudra Prasanna Mishra,

Postgraduate Resident,

Department of Community Medicine,

VIMSAR, Burla, Odisha.

E-mail: dr.mishra.rudra@gmail.com

DOI: $10.14260 /$ jemds $/ 2018 / 328$

\section{(c) $(i) \Theta$}

Due to the success of modern medicine such deaths have become very rare in developed countries, which has led to an increased interest in analysing so-called "near miss" events. ${ }^{5}$

Maternal mortality is a critical indicator to assess the quality of services provided by a health care system. The standard indicator for measuring it is the Maternal Mortality Ratio (MMR) defined as the ratio of the number of maternal deaths per 100,000 live births. Globally, there has been decline in MMR in India too. This is declining steadily due to the additional efforts and resources put under NHM for improving healthcare. There is a need to further accelerate this decline for achieving our National and International goals and targets under them. ${ }^{6}$

Near miss is defined as very ill pregnant or recently delivered woman who nearly died but survived a complication during pregnancy, childbirth or within 42 days of termination of pregnancy. Severe acute maternal morbidity (SAMM) refers to life-threatening disorders that can end up in near miss with or without residual morbidity or mortality. Women who develop SAMM during pregnancy share many pathological and circumstantial factors related to their condition. Although, some of these women die, a proportion of them narrowly escape death. Near miss cases and maternal deaths together are referred to as severe maternal outcome (SMO). ${ }^{7}$ 
WHO recommended three different approaches of selection criteria for identification of MNM cases. They are disease specific, management based and organ dysfunction. Disease-specific morbidities are severe pre-eclampsia, eclampsia, severe haemorrhage, severe sepsis and uterine rupture, however have too low threshold of morbidity to be called near miss. Management based criteria are according to specific intervention made, e.g. admission to ICU, procedure such as obstetric hysterectomy, massive blood transfusion, intubation and ventilation. ${ }^{8}$

\section{Objectives}

1. To estimate the burden of maternal near miss in 0 and $G$ Dept. of VIMSAR, Burla in terms of proportion and near miss indicators.

2. To assess the foetal outcome of patients with maternal near miss.

\section{MATERIALS AND METHODS}

This is a record-based cross-sectional study conducted in Obstetrics and Gynaecology (O and G) Department, VIMSAR, Burla from July 2017 to Dec 2017. Potentially diagnosed lifethreatening conditions and those cases which met WHO 2009 criteria of "near miss" case definition were selected and their details were obtained from the secondary data sources, i.e. from case records and individual case sheets.

\section{Case Definition}

In order to capture the most cases that had a life-threatening complication but did not die (i.e. a 'near-miss'), the case definition was adapted to include-

a. Clinical diagnostic criteria of morbidity from obstetric complications focusing on the major causes of maternal mortality i.e. haemorrhage, hypertensive disorders, abortion and sepsis.

b. Criteria based on management such as admission to an intensive care unit for patients whose condition was considered as life threatening.

c. Major interventions such as emergency post-partum hysterectomy, immediate blood transfusion.

\section{Data Collection}

1. Timing and Site: All patients meeting the case definition in the Department of Obstetrics and Gynaecology of VIMSAR, Burla over a period of July 2017 to December 2017.

2. Data Source(s): Delivery record, emergency admission record and the admission log of patients admitted to the labour ward.

3. Data Collection Methods: After approval of Institutional Ethics Committee, a daily review was made of registers identifying patients that potentially had a life-threatening complication. If the patient met the criteria of the case definition of a 'near miss,' the details were obtained from the patient's case records.

\section{RESULTS}

During 6 months of study period, total no. of deliveries were 1406 and total no. of live births were 1349 , out of which near miss cases were 89 and 8 cases were of maternal death.

\begin{tabular}{|c|c|c|c|}
\hline Sl. No. & Characteristics & Near Miss Cases & $\%$ \\
\hline \multirow[t]{4}{*}{1} & Age Group (N=89) & & \\
\hline & $\leq 19$ years & 6 & 6.7 \\
\hline & 20-34 years & 77 & 86.5 \\
\hline & $\geq 35$ years & 6 & 6.7 \\
\hline \multirow[t]{3}{*}{2} & Gravida $(N=89)$ & & \\
\hline & Primigravida & 42 & 47.2 \\
\hline & Multigravida & 47 & 52.8 \\
\hline \multirow[t]{3}{*}{3} & Parity $(\mathrm{N}=41)$ & & \\
\hline & Primipara & 28 & 68.3 \\
\hline & Multipara & 13 & 31.7 \\
\hline \multirow[t]{3}{*}{4} & $\begin{array}{c}\text { Gestational Age } \\
(\mathrm{N}=89)\end{array}$ & & \\
\hline & $\leq 28$ weeks & 3 & 3.4 \\
\hline & $>28$ weeks & 86 & 96.6 \\
\hline & Table 1. Demogra & Characteristics & \\
\hline
\end{tabular}

Table 1 shows $86.5 \%$ of near miss cases which were found in 20 to 34 years of age group. Multigravida (52.8\%) cases were slightly more in near miss cases, but in case of primipara the near miss cases were higher i.e. 63.8\%. Majority of the near miss cases were in the third trimester (96.6\%).

\begin{tabular}{|c|c|c|}
\hline Morbidity Conditions & Frequency & Percentage \\
\hline Haemorrhage & 6 & 6.7 \\
\hline Severe Pre-eclampsia & 36 & 40.4 \\
\hline Eclampsia & 17 & 19.1 \\
\hline Severe anaemia & 26 & 29.2 \\
\hline Infection & 2 & 2.2 \\
\hline Heart disease & 1 & 1.1 \\
\hline Critical Interventions & Frequency & Percentage \\
\hline Use of blood product & 51 & 35.9 \\
\hline Laparotomy & 21 & 23.5 \\
\hline ICU admissions & 14 & 15.7 \\
\hline \multicolumn{3}{|c|}{$\begin{array}{l}\text { Table 2. Morbidity Conditions and Critical } \\
\text { Interventions in Near Miss Cases }\end{array}$} \\
\hline
\end{tabular}

Among the complications of near miss cases severe preeclampsia was the leading cause (40.4\%) of morbidity followed by severe anaemia (29.2\%), eclampsia (19.1\%) and infection $(2.2 \%)$. Analysis of critical intervention shows that $35.9 \%$ of near miss cases required blood transfusions as part of their immediate management. $15.7 \%$ cases were sick enough to be admitted to ICU and laparotomy was done in $23.5 \%$ of near miss cases to save their life.

\begin{tabular}{|c|c|c|c|}
\hline Sl. No. & Characteristics & Frequency & Percentage \\
\hline 1 & Mode of Delivery & & \\
\hline & Vaginal & 41 & 46.1 \\
\hline & C-Section & 48 & 53.9 \\
\hline 2 & Neonatal Condition & & \\
\hline & Live birth & 82 & 92.1 \\
\hline & Still birth & 7 & 7.9 \\
\hline 3 & Birth Weight & & \\
\hline & $<1.5 \mathrm{~kg}$ & 5 & 5.6 \\
\hline & $1.5-2.5 \mathrm{~kg}$ & 39 & 43.8 \\
\hline \multicolumn{2}{|c|}{ Table 3. Obstetric and Perinatal Outcome } \\
\hline \multicolumn{3}{|c|}{} \\
\hline
\end{tabular}

Obstetric and perinatal outcome (Table 3) shows that Caesarean section was done in $53.1 \%$ ( 48 cases) of near miss cases, while $46.1 \%$ (41 cases) had normal delivery. The live birth rate was $92.1 \%$ (82) from near miss cases. Babies weighing between $1.5-2.5 \mathrm{~kg}$ were $43.8 \%$. 


\begin{tabular}{|c|c|}
\hline Outcomes & $\begin{array}{l}\text { Near Miss } \\
\text { Indicators }\end{array}$ \\
\hline All live births & 1349 \\
\hline SMO cases & 97 \\
\hline Maternal deaths & 08 \\
\hline Maternal near miss cases & 89 \\
\hline Overall Near Miss Indicators & \\
\hline SMOR (per 1000 live births) & 71.9. \\
\hline Maternal near miss ratio/ 1000 live births & 65.97 \\
\hline Maternal near miss mortality ratio & 11.1 \\
\hline *Mortality index (\%) & 8.2 \\
\hline **SM012(n) & 68 \\
\hline $\begin{array}{c}\text { Proportion of SM012 cases among all SMO } \\
\text { cases }\end{array}$ & $70.1 \%$ \\
\hline $\begin{array}{l}\text { Proportion of SM012 cases referred from other } \\
\text { health facility }\end{array}$ & $60.82 \%(59)$ \\
\hline
\end{tabular}

*Mortality Index: The number of maternal deaths divided by the number of women with life-threatening conditions expressed in terms of percentage.

**SM012: Cases presenting with organ dysfunction or maternal death within 12 of hospital stays.

Analysis of near miss indicators (Table 4) show that maternal near miss incidence ratio (MNMIR) was 65.97/1000 live births. Maternal near miss mortality ratio (MNMR) was 11.1 and mortality index was $8.2 \%$. Maternal mortality ratio was found to be 593/ 1,00,000 live births. There was a total of 68 SM012 cases in our study. Of those 68 SM012 cases, 59 cases $(60.82 \%)$ were referral cases.

\section{DISCUSSION}

The primary determinant of near miss cases in our study was severe preeclampsia (40.4\%). An observational study conducted by Chandan JR et al also observed preeclampsia that comprised of $(23.5 \%)$ which is the leading cause of maternal near miss case.(2) Souza et al from Brazil also reported hypertensive disorder as the most commonly associated (57\%) cause of near miss cases. ${ }^{(9)}$ Severe anaemia (29.2\%) was the second cause of maternal near miss cases. This finding collaborated with Bansal M et al study.(1) Lower rates of death due to infection in our study indicate better quality at our facility.

Majority (86.5\%) were in the age group of 20 - 34, which was similar to the study conducted by Chandan JR et al.(2) Multigravida (52.8\%) were more than primigravida(2) in our study. However, in other studies, majority were primigravida.(2) In our study, caesarean section (CS) was done in $53.1 \%$ of near miss cases which was $37.5 \%$ in other study.(10)

The maternal near miss to mortality ratio (MNMR) was 11.1: 1 in our institution. Studies done in the developing countries vary from anywhere between $7-40 / 1000$ live births.(11-13) The maternal near miss incidence ratio (MNMIR) was 65.97 per 1000 live births, but studies show 15 - 40 per 1000 live births in the developing countries. Mortality index was 8.2 in our setup, which was similar to the study conducted by Chandan JR et al(2) and lower value of maternal index was found compared to study conducted by Tallapureddy et al.(14)

Even with improving care, maternal near miss incidence (65.97 per 1000 live births) was found to be higher in our institution for probably being a tertiary care centre. However, high maternal near miss to mortality ratio index (11.1) and low mortality index (8.2\%) shows better quality care in our setup. In our study, referred near miss cases from other health facilities were higher. This clearly shows that near miss cases seek health care at the last minute of golden hour, which might be due to various reasons. So near miss cases are due to delayed referral; it may be first delay or second delay. Study limitation includes prospective follow-up of patients, which might have yielded more information. However, this would have required community follow-up.

\section{CONCLUSION}

From this study, we conclude that near miss cases can be prevented by improving the quality of maternal health care in individual healthcare facility. Timely referral after first line therapy would play very important role to save lives of pregnant mothers. Timely management of maternal near miss cases is very important. Based on our findings, we recommend the following actions should be taken by the Government to reduce the maternal near miss and maternal death-

1. Early identification of risk factors for preeclampsia and prompt initiation of treatment.

2. Improving antenatal care to prevent severe anaemia and pre-eclampsia.

3. Availability of blood bank facility.

4. Ventilator support should be mandatory in first referral units.

\section{REFERENCES}

[1] Bansal M, Lagoo J, Pujari K. Study of near miss cases in obstetric and maternal mortality in Bastar, Chhatisgarh, India. Int J Reprod Contracept Obstet Gynecol 2016;5(3):620-3.

[2] Chandran JR, Raj SV, Devi SD, et al. Maternal near miss review from a tertiary care center in South India. Int J Reproduction, Contraception, Obst \& Gyn 2016;5(8):2657-60.

[3] WHO. Declaration of Alma Ata. International Conference on Primary Health Care. Alma. USSAR, 1978:6-12.

[4] Rööst M, Altamirano VC, Liljestrand J, et al. Priorities in emergency obstetric care in Bolivia maternal mortality and near-miss morbidity in metropolitan La Paz. BJOG 2009;116(9):1210-7.

[5] Dott MM, Orakail N, Ebadi H, et al. Implementing a facility-based maternal and perinatal health care surveillance system in Afghanistan. Journal of Midwifery \& Women's Health 2005;50(4):296-300.

[6] Maternal Near Miss Review, Operational Guideline, Maternal Health Division, Ministry of Health and Family Welfare, Government of India. Dec 2014:1.

[7] Chhabra P. Maternal near miss: an indicator for maternal health and maternal care. IJCM 2014;39(3):132-7.

[8] Waterstone M, Bewley S, Wolfe C. Incidence and predictors of severe obstetric morbidity: case-control study. BMJ 2001;322(7294):1089-94. 
[9] De Souza JP, Cecatti JG. The near miss maternal morbidity scoring system was tested in a clinical setting in Brazil. J Clin Epidemiol 2005;58(9):962-3.

[10] Morse ML, Fonseca SC, Gottgtroy CL, et al. Severe maternal morbidity and near misses in a regional reference hospital. Rev Brass Epidemiol 2011;14(2):310-22.

[11] Lotufo FA, Parpinelli MA, Haddad SM, et al. Applying the new concept of maternal near-miss in an Intensive Care Unit Clinic (Sao Paulo) 2012;67(3):225-30.
[12] Van Roosmalen J, Zwart J. Severe acute maternal morbidity in high-income countries. Best Pract Res Clin Obstet Gynaecol 2009;23(3):297-304.

[13] Souza JP, Cecatti JG, Parpinelli MA, et al. Appropriate criteria for identification of near miss maternal morbidity in tertiary care facilities: a cross sectional study. BMC Pregnancy Childbirth 2007;7:20.

[14] Tallapureddy S, Velagaleti R, Palutia H, et al. Near miss obstetric events and maternal mortality in a tartiary care hospital. Indian $\mathrm{J}$ of Public Health 2017;61(4):305-8. 